\title{
Analysis of shifting and reduction of the demand peak with the inserting of photovoltaic systems in the Neoville's Headquarters of Federal University of Technology - Paraná Curitiba Campus
}

\author{
Juliana D'Angela Mariano ${ }^{{ }^{*}}$, Jair Urbanetz Junior ${ }^{1,2}$ \\ ${ }^{1}$ Programa de Pós-Graduação em Engenharia Civil, Universidade Tecnológica Federal do Paraná, Curitiba, \\ Brasil; ${ }^{2}$ Programa de Pós-Graduação em Sistemas de Energia, Universidade Tecnológica Federal do Paraná, \\ Curitiba, Brasil.
}

\begin{abstract}
Photovoltaic solar energy is increasingly present in the urban environment through the distributed generation. This kind of generation is characterized by the installation along the distribution network feeders, in low or medium voltage, and contribute to provide energy near the point of consumption. In this sense, this study aims to analyze the demand and consumption curves of the buildings of the Federal University of Technology - Paraná (UTFPR) in the Neoville's headquarters. The methodology consists in the application of COPEL'S CAS Hemera platform, in order to determine the potential for the implementation of the Grid-Connected Photovoltaic Systems in this place, because they allow the reduction of costs with electric energy from the application of distributed generation. In February 2016, a grid-connected photovoltaic system was installed in one of the university's blocks, which generated approximately $11 \mathrm{MWh}$ of electric energy this year. This work proposes a scenario for the expansion of this photovotaic system and presents the contribution of photovoltaic generation, using the available coverage showing the shifting or reduction of energy demand peaks and the energy contribution to UTFPR's Neoville headquarters. The results of this study show that the proposed scenario will effectively change the profile of the university demand curve.
\end{abstract}

Keywords: photovoltaic system, energy contribution, power generation.

*Author for correspondence: julianadangela@gmail.com 


\section{INTRODUCTION}

The grid-connected photovoltaic systems are seen as a form of distributed generation along the distribution grid feeders, in low or medium voltage, and contribute to provide energy near the point of consumption ${ }^{1}$.

After the implementation of the ANEEL (Brazilian National Electric Energy Agency) 482 regulations, there was a significant increase in the installation of micro (up to $75 \mathrm{~kW}$ ) and mini (up to $5 \mathrm{MW}$ ) photovoltaic power plants in Brazil. According to ${ }^{2}$, there were approximately 12,000 photovoltaic generating units in Brazil until July 2017 , totaling approximately $96 \mathrm{MWp}$, thus totaling around $240 \mathrm{MWp}$ of the gridconnected photovoltaic system in Brazil.

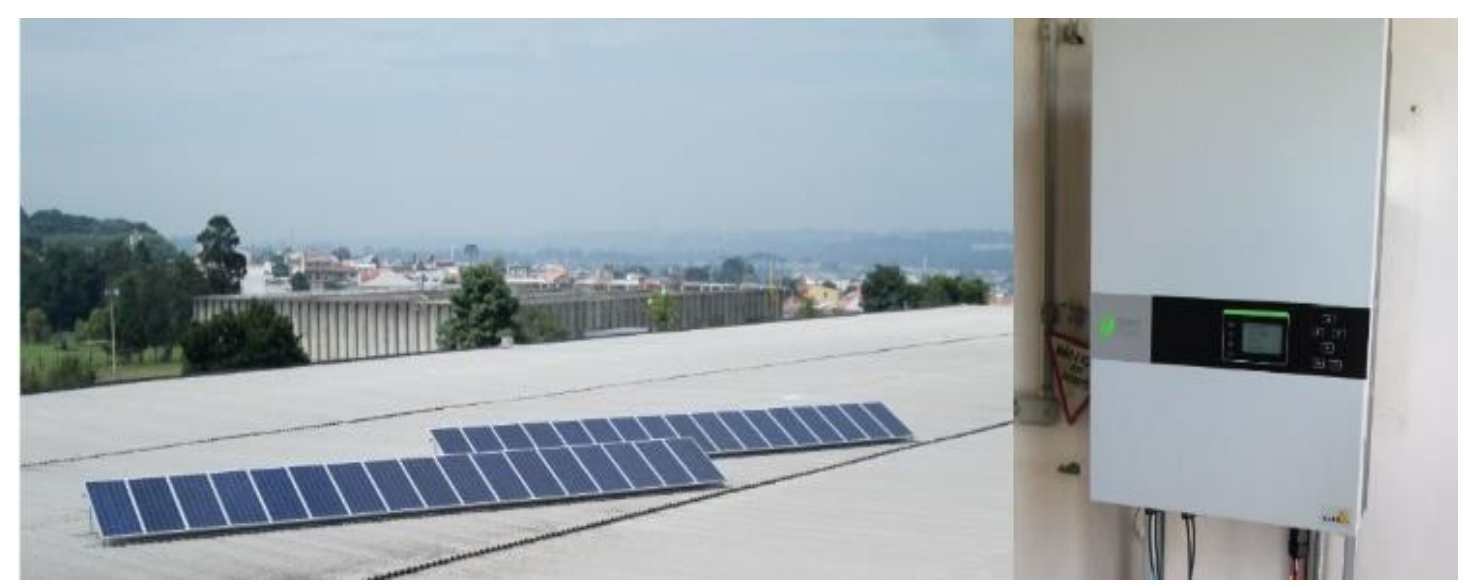

Figure 1 - Grid-Connected Photovoltaic System and Inverter of UTFPR - Curitiba

Following this trend, in February 2016, a grid-connected photovoltaic system was installed in the Neoville's headquarters of UTFPR's Curitiba campus, which was provided by the company Elco Engenharia. The photovoltaic system (Figure 1) presents a total installed power of $10.2 \mathrm{kWp}$, consisting of 2 sets of 17 photovoltaic modules connected in series, model: ELCO-A300P, totaling 34 modules of $300 \mathrm{Wp}$ polycrystalline silicon in each module. The area covered on the roof for this panel is approximately $68 \mathrm{~m}^{2}$, and the inverter used in the system is the Chint Power brand, three-phase and transformerless $380 \mathrm{~V}$ high performance model: CPS SCA 10KTL-DO and rated power output of $10 \mathrm{~kW}^{3}$.

Regarding the allocation of photovoltaic modules, the orientation was chosen according to the geographic coordinates of latitude $-25.50^{\circ}$ and longitude $-49.32^{\circ}$. Under this condition it was possible to reach the optimal conditions of installation and these were fully installed on the roof of UTFPR's block 1, which has a support structure located below it on a concrete slab.

The average monthly generation of the grid-connected photovoltaic system of the Neoville's headquarters in UTFPR was $1,082.70 \mathrm{kWh} /$ month and the average daily generation was $36.09 \mathrm{kWh}$, according to the monitoring of the first ten months shown in Figure 2. A total generation was observed until December 2016 of 10.57 MWh. Therefore, the prediction is that all energy production will be for UTFPR's own use, avoiding the application of the compensation system regulated by ANEEL, thus contributing to reduce the consumption of electric energy in the Curitiba campus. 


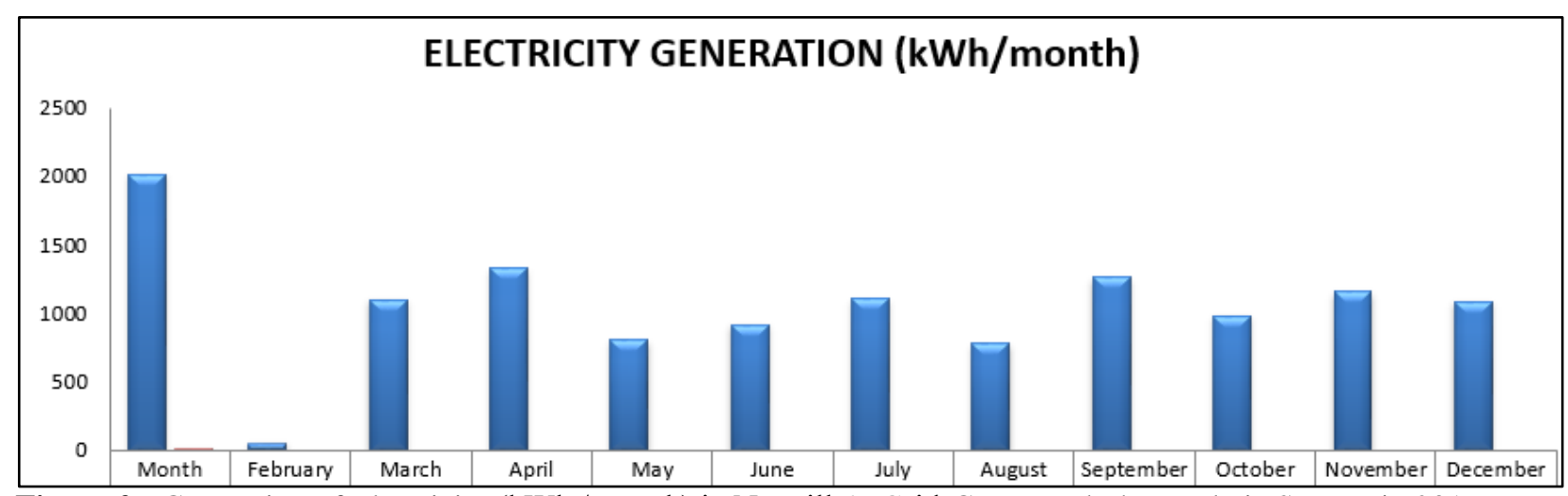

Figure 2 - Generation of Electricity (kWh / month) in Neoville's Grid-Connected Photovoltaic System in 2016

With the proposed expansion of this system, a generation superior than consumption is expected, being able thus to contribute with the reduction of consumption in other branches. Consequently, from the production and performance data of this system, it is possible to design scenarios and predict the behavior and functioning for other branches and the expansion of the grid-connected photovoltaic system present at Neoville's headquarters.

It is important to highlight that the grid-connected photovoltaic system installed at the Neoville's headquarters has met technical standards related to the subject, such as NBR 16274: 2014 - Grid-Connected Photovoltaic System, ABNT NBR 11876: 2010 Photovoltaic Modules, Module 3 of PRODIST.

\section{MATERIAL AND METHODS}

The study of the feasibility of the expansion of the existing grid-connected photovoltaic system, included several steps described below. In this sense, the first step refers to the survey of the solar resource, which was done through the Brazilian Atlas of Solar Energy ${ }^{4}$, which presents values of solar irradiation for the inclined plane for the longitude and latitude of the place, calculation of monthly and annual energy. Afterwards, the criterion of choice of the typical days for consumption and demand analysis was adopted, using typical days of irradiation, using INMET meteorological data in 2016 and coinciding with the academic calendar ${ }^{5}$.

Thus, the analysis of the coverage areas, ie roofs and locations available for the allocation of the photovoltaic modules at the Neoville's headquarters is carried out by means of the evaluation of the floor plans made available by the Department of Projects (DEPRO) of the UTFPR Curitiba campus and survey in loco, aiming also to avoid the aesthetic commitment of the building, and at the same time to determine the photovoltaic potential of the campus.

The grid-connected photovoltaic system sizing can be started from the available area and the area of the photovoltaic modules, according to Equation $1^{6}$.

$$
N_{\bmod }=\frac{\text { Areaavail }}{\text { Areamod }}
$$

Where:

$\mathrm{N}_{\text {mod: }}$ number of modules;

Area $_{\text {avail: }}$ available area;

Area $a_{\text {mod: }}$ area of modules added to the spacing area avoiding shading between rows. 
From the power of the module and its quantity it is possible to calculate the value of the installed peak power of the panel or arrangement, according to Equation $2^{6}$.

$$
P_{P V}=P_{\bmod } N_{\bmod }
$$

Where:

$\mathrm{P}_{\mathrm{PV}}$ : installed peak photovoltaic power $(\mathrm{Wp})$;

$\mathrm{P}_{\text {mod: }}$ power of the modules;

$\mathrm{N}_{\text {mod: }}$ number of modules.

In order to maximize annual generation in a grid-connected photovoltaic system, the slope of the modules must correspond to local latitude, in the case of Curitiba, $25^{\circ}$ and geographic north. The daily average irradiance values in the photovoltaic panel plane are estimated, the average daily generation of electricity is estimated through Equation $3^{6}$.

$$
E=\frac{P_{P V} \times H_{T O T} \times P R}{G}
$$

Where:

E: average daily electrical energy (Wh/day);

PPV: installed peak photovoltaic power (Wp);

HTOT: monthly average daily solar irradiation for the locality in question (Wh/ $/ \mathrm{m}^{2}$.day);

PR: Performance Fee or Performance Ratio, typically between 70 and 80\% (75\% for this analysis);

G: irradiance in the Standard Test Conditions $\left(1,000 \mathrm{~W} / \mathrm{m}^{2}\right)$.

From the monthly values of electric energy produced by the grid-connected photovoltaic system calculated in Equation 3, it is possible to analyze the contribution of the proposed photovoltaic generator, in relation to the energy produced and overlapping the photogenerated power curve with the demand curve, making it possible to identify the possible contribution in reduction of peak demand.

In order to collect data on the consumption and energy demand, that is, mass memories of the electric energy meter of the Neoville's headquarters, the platform called CAS Hemera7 was used.

In terms of reduction of energy consumption, a parameter for analysis of the results will be the Energy Penetration Level (EPL), calculated according to Equation 4.

$$
E L P=\frac{E_{P V P L}}{E_{S E}} \times 100
$$

Where:

EPVPL: Energy generated by the photovoltaic system with determined Penetration Level (PL), over a day or year (MWh);

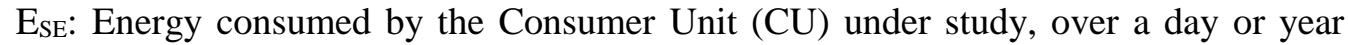
(MWh).

For the calculation of the energy generated by the photovoltaic system with determined NP, during one day (MWh), Equation 5 is used.

$$
E_{P V P L}=P_{P V P L} \times H_{T O T A} \times 365 \times P R
$$

where: 


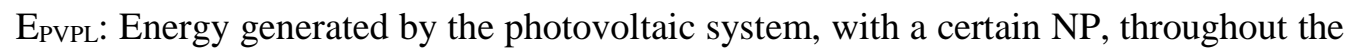
year, GWh;

$\mathrm{P}_{\mathrm{PVPL}}$ : Peak photovoltaic power, defined as NP (MWp);

$\mathrm{H}_{\text {TотА }}$ : average annual solar irradiation for the city of Curitiba ( $\mathrm{Wh} / \mathrm{m}^{2}$.day);

PR: Performance Ratio or system performance rate, considered equal to 0.75 .

The parameter applied for the demand reduction analysis is an analysis of the Effective Load Capacity Factor (ELCF), which consists of subtracting from the peak of the demand curve of this day the peak of the curve equivalent to the demand of the feeder in question when the grid-connected photovoltaic systems are inserted and soon after dividing this value by the grid-connected photovoltaic system installed nominal capacity, as shown in Equation $6^{8}$.

$$
E L C F=\frac{P_{D M A X}-P_{D M A X P V}}{P_{P V P L}} \times 100
$$

Where:

ELFC: Effective Load Capacity Factor,\%;

$P_{\text {DMAX: }}$ Maximum demanded power in the day without the photovoltaic contribution;

$P_{\text {DMAXPV: }}$ Maximum demanded power in the day with the photovoltaic contribution;

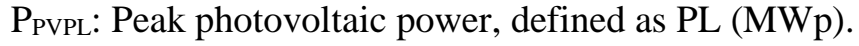

\section{RESULT AND DISCUSSION}

Table 1 shows the values of irradiance in the inclined plane obtained in the Brazilian Atlas of Solar Energy, considering $25^{\circ}$ for inclination of the photovoltaic panel and azimuthal deviation of $0^{\circ}$ towards the north.

Table 1 - Radiation Data on the Inclined Plane to Neoville's Headquarters Data acquired through the Brazilian Atlas of Solar Energy ${ }^{4}$

\begin{tabular}{ccccccccccccccc}
\hline \multicolumn{11}{c}{ GLOBAL IRRADIATION (ATLAS) - kWh/m $\mathbf{m}^{2}$.day } \\
\hline LONG & LAT & JAN & FEB & MAR & ABR & MAY & JUN & JUL & AUG & SEP & OCT & NOV & DEC & ANNUAL \\
-49.18 & -25.33 & 5.14 & 5.33 & 5.58 & 4.92 & 4.48 & 4.48 & 4.26 & 5.31 & 4.93 & 5.00 & 5.48 & 5.17 & 4.98 \\
\hline
\end{tabular}

Additionally, a survey of the daily radiation values incident in the city of Curitiba was carried out in March and June 2016, a period that includes the academic calendar of the institution and approaching summer and winter. In these measurements, the typical days of maximum and minimum irradiation obtained were days 03/17/2016 and 06/15/2016 respectively, and they will be used in this analysis.

Table 2 shows the irradiance values obtained on these dates from the INMET meteorological data.

Table 2 - Typical Days Selected

\begin{tabular}{ccc}
\hline Date & Irradiation & Daily Irradiation $\left(\mathrm{kWh} / \mathrm{m}^{2}\right.$.day) \\
\hline $03 / 17 / 2016$ & Typical & 5.75 \\
$06 / 15 / 2016$ & Typical & 3.83 \\
\hline
\end{tabular}

Data acquired through the INMET ${ }^{5}$ database

After performing the shading analysis, the most suitable blocks for the application of photovoltaic modules were identified: $1 \mathrm{~A}, 2,3,4 \mathrm{~A}$ and $4 \mathrm{~B}, 5,7,8,9$ and 10 as indicated in Figure 3, because they present their coverings with little slope and without shadowing by adjacent buildings or vegetations. Thus, the total area of the blocks 
selected for the grid-connected photovoltaic system implantation is approximately $21,000 \mathrm{~m}^{2}$ according to Figure 3 .

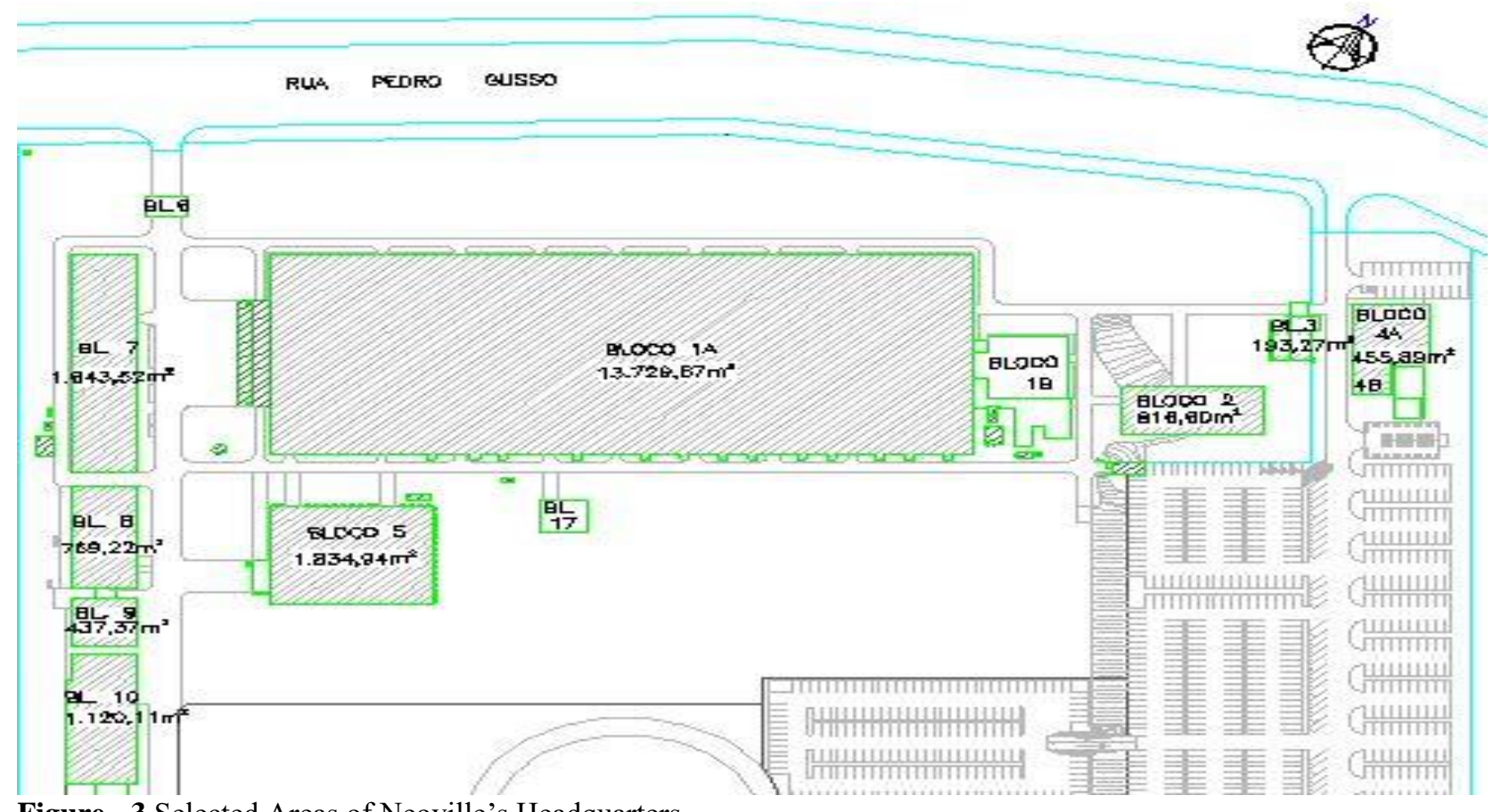

Figure - 3 Selected Areas of Neoville's Headquarters

For the design of proposed grid-connected photovoltaic system, the 330Wp Hareon Solar photovoltaic module was used, which presents an area of $1.94 \mathrm{~m}^{2}$. However, it is necessary to add the area of spacing, that is, the distance between modules, in order to avoid shading between the rows $\left(1.65 \mathrm{~m}^{2}\right)$, reaching a total area required per module of $3.45 \mathrm{~m}^{2}$. In this way, Equation 1 was applied, obtaining the number of modules equal to 6,086 .

$$
N_{\text {mód }}=\frac{21,000 m^{2}}{3.45 m^{2}} \quad N_{m o d}=6,086
$$

With the number of modules it is possible to calculate the power of the photovoltaic generator by applying Equation 2, obtaining an installed power of 2,008.38 kWp.

$$
P_{P V}=330 \times 6,086 \quad P_{P V}=2,008.38 \mathrm{kWp}
$$

Therefore, with the value of the installed power, annual average irradiance obtained in the Brazilian Atlas of Solar Energy for the inclined plane and Performance Ratio of 0.75, it is possible to estimate, through Equation 3, the values of average monthly and annual electricity generation described in MWh in Table 3.

$$
E=\frac{2,008.38 \times 4.98 \times 0.75}{1} \quad E=7,501.30 \mathrm{kWh} / \text { day }
$$

Table 3 - Monthly and Annual Average Power Generation of the Neoville's Headquarters

\section{POWER GENERATION (MWh)}

\begin{tabular}{ccccccccccccc}
\hline JAN & FEB & MAR & ABR & MAY & JUN & JUL & AUG & SEP & OCT & NOV & DEC & ANNUAL \\
240.01 & 224.80 & 260.56 & 222.33 & 209.19 & 202.44 & 198.92 & 247.95 & 222.78 & 233.47 & 247.63 & 241.41 & $2,737.97$ \\
\hline
\end{tabular}

Values calculated considering the proposed grid-connected photovoltaic system 
Note that the estimated daily energy is $7,501.30 \mathrm{kWh} /$ day, while the total annual value to be produced by a grid-connected photovoltaic system is 2,737.97 MWh/year. The proposed analysis made the determination of the potential for photovoltaic generation of the Neoville's headquarters of UTFPR possible, resulting in a system approximately 196.9 times larger than the existing photovoltaic system. Based on this result, it is proposed a scenario of expansion of the existing system at headquarters, extrapolating the obtained power values (196.9x) on the days listed for the analysis.

Table 4 shows the consumption data for this site, as well as the total photogenerated energy considering the instantaneous grid-connected photovoltaic system inverter (increased by 196.9) installed in this site and the respective percentages of energy reduction for the days listed for the analysis, where the month of March presented greater potential for energy reduction in general, due to the greater availability of solar irradiation.

Table 4 - Consumption, Photogenerated Energy, and Reduction Percentage of Neoville's Headqaurters

\begin{tabular}{cccc}
\hline Date & $\begin{array}{c}\text { Total Daily } \\
\text { Consumption }(\mathrm{kWh})\end{array}$ & $\begin{array}{c}\text { Total Photogenerated Energy } \\
(\mathrm{kWh})\end{array}$ & $\begin{array}{c}\text { Reduction Percentage } \\
(\%)\end{array}$ \\
\hline $03 / 17 / 2016$ & 2,012 & 9,698 & $482.0 \%$ \\
$06 / 15 / 2016$ & 2,001 & 9,160 & $457.8 \%$ \\
\hline
\end{tabular}

Values calculated considering the proposed grid-connected photovoltaic system.

According to Table 4, the typical irradiation days of March and June present an equivalent energy reduction potential, and because this site presents the low consumption, but a wide availability for expansion of the existing grid-connected photovoltaic system, its percentages of reduction were shown much higher, and can export energy to the power distribuition company, generating credits to be used in the other headquarters of the UTFPR - Curitiba campus.

Figure 4 shows the UTFPR demand curve for the selected day, obtained on the CAS Hemera platform. According to the graphs generated by the CAS Hemera platform, the demand provided by COPEL, measured at UTFPR's Neoville headquarters, showed a peak value of demand for electricity at 06:00am,registered a value of 145 $\mathrm{kW}$ on 03/17/2016. Yet, for a typical day of irradiation of June, the time of greatest demand occurred at 08:00am registering a power of $118 \mathrm{~kW}$ on 06/15/2015. 


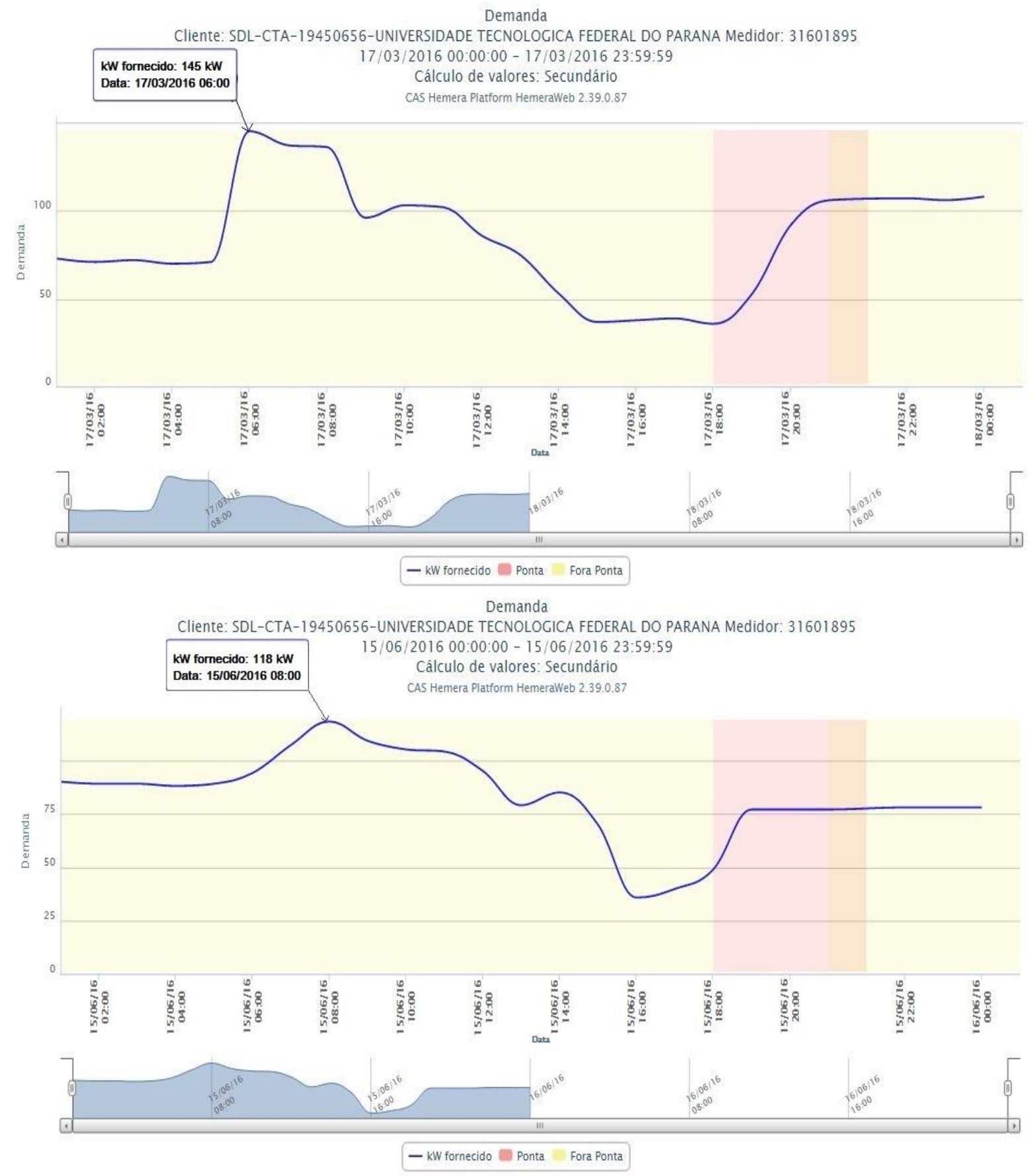

Figure 4 - Demand Curves

Figure 5 shows the behavior of the demand that would be observed at Neoville's headquarters on 03/17/2016 and 06/15/2016 considering the existence of the proposed grid-connected photovoltaic system of 2,008.38 kWp.

The overlapping of demand curves provided with the calculated power was obtained, resulting in a considerable change in demand behavior over the course of the day. In this sense, it is also observed the possibility of occurrence of injection of surplus energy in the local power grid in the period between 07:00 and 18:00 and from 09:00 to 16:00, respectively, reaching its maximum point of injection at 13:00 and 12:00, period when the grid-connected photovoltaic system reaches its maximum power. 

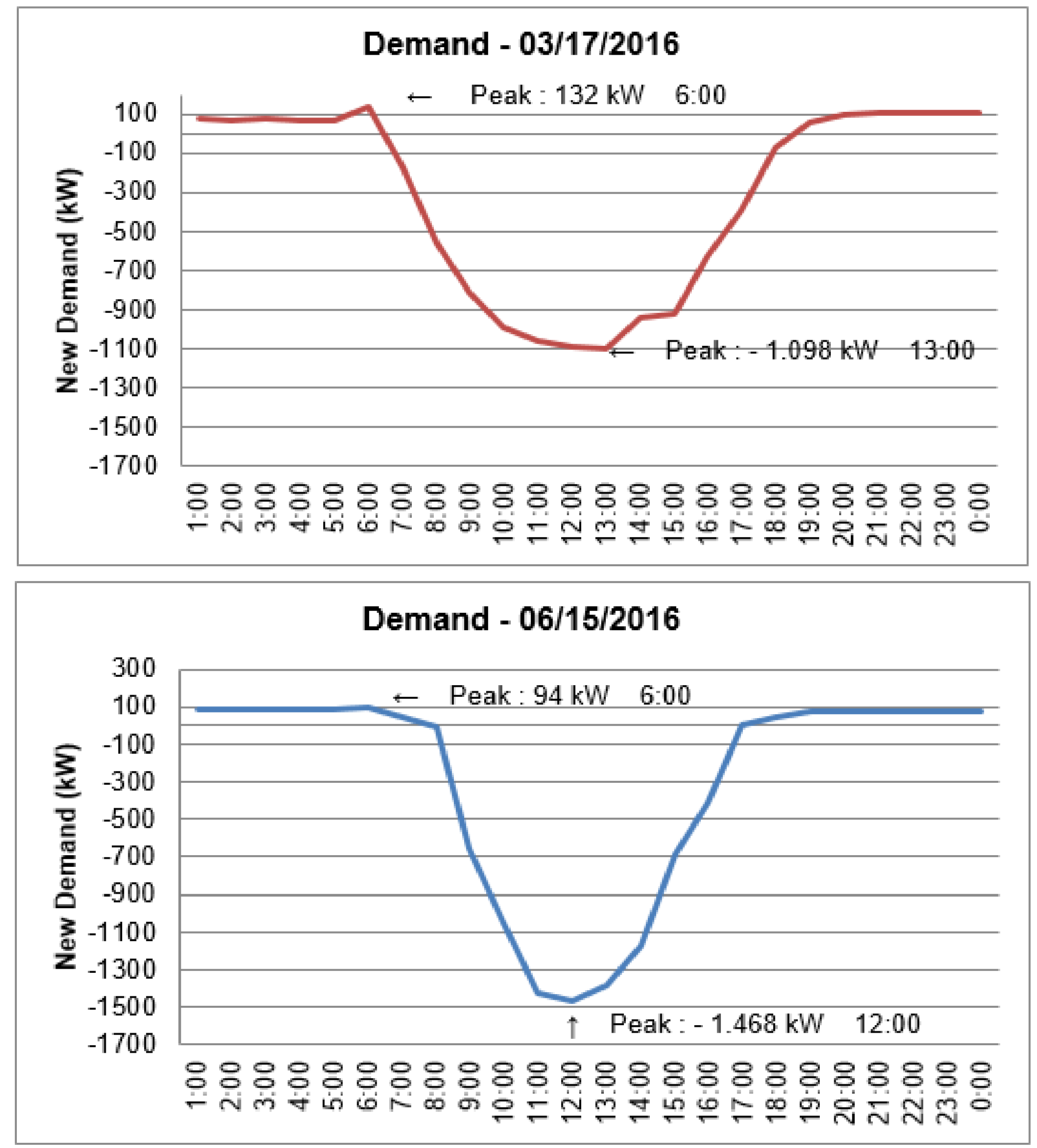

Figure 5 - New Demand Curve

The total energy consumed in this headquarters in 2016 was $626.70 \mathrm{MWh}$ and the energy generated by a grid-connected photovoltaic system of $2,008.38 \mathrm{kWp}$ would be 2,737.97 MWh. Applying analysis parameters by calculating the Energy Penetration Level (EPL), Equation 4:

$$
E P L=\frac{2.737,97}{626.70} \times 100 \quad E P L=436.88 \%
$$

Therefore, from the application of this equation we obtained an EPL of $436.88 \%$ reduction of electricity with the implementation of a system of 2,008.38 kWp. From this result of EPL above $100 \%$, it means that the energy produced in excess can be exported to other UTFPR sites. 
For the analysis of the chosen days, with regard to the reduction of the demand peaks, Equation 6 was used and its results are presented in Table 5.

Table 5 - Calculation of LFEF For Neoville's Headquarters

\begin{tabular}{cccc}
\hline \multicolumn{3}{c}{ Effective Load Capacity Factor } \\
$(2,008.38 \mathrm{kWp})$ & LFEF $(\%)$ \\
\hline Day & Demand & New Demand & 0.7 \\
$03 / 17 / 2016$ & 145 & 132 & 1.2 \\
$06 / 15 / 2016$ & 118 & 94 & \\
\hline
\end{tabular}

Values calculated considering the proposed grid-connected photovoltaic system.

According to the data presented in Table 5, it is observed that the maximum reduction of demand peaks occurs on $06 / 15 / 2016$, resulting in a ELCF of $1.2 \%$. However, on $03 / 17 / 2017$, due to the displacement of demand peaks for times when there is no energy contribution, there are no significant reductions.

\section{CONCLUSION}

The proposed analysis enabled the determination of the potential for photovoltaic generation of the UTFPR Neoville's headquarters, resulting in a system approximately 197 times larger than the existing grid-connected photovoltaic system. Thus, the proposed expansion represents an installed capacity of $2,008.38 \mathrm{kWp}$, resulting in an average daily electricity production of 7,501.30 kWh and 2,737.97 MWh /year.

Although the calculated EPL was $436.88 \%$, the ELCF indexes ranged from $0.7 \%$ to $1.2 \%$ due to the occurrence of demand peaks in the days analyzed, at times when there is no contribution from the PV generator.

Due to the demand of this site being low and the area available for the grid-connected photovoltaic system being very extensive, there would be injection of the surplus of photogenerated energy even in the days of low availability of solar irradiation, as the result of the EPL was shown to be greater than $100 \%$ and could be exported to other branches, according to ANEEL's compensation system, including other cities' headquarters.

It should be emphasized that the proposed scenario used the power profile provided by the existing grid-connected photovoltaic system $10.2 \mathrm{kWp}$ at UTFPR's Neoville headquarters and in operation since February 2016, so the proposed system of $2,008.38 \mathrm{kWp}$ will effectively cause a change in the profile of the curve of university demand as demonstrated in the analyzed days.

In addition to the possibility of reducing electricity costs, there would be a significant reduction in GHG emissions, which could avoid significant amounts of $\mathrm{CO}_{2}$ emissions to the National Interconnected System (SIN) in the country.

Thus, it can be concluded that the application of strategies that use photovoltaic generation presents itself as a sustainable solution, since the implementation of gridconnected photovoltaic system confirms the hypotheses raised of increase in the supply of energy in the electric system, promotion of the reduction of GHG's in the electrical matrix of Curitiba, and the possibility of changing the demand profile from the application of energy efficiency strategies, making its operation more effective.

Therefore, the study indicates that the insertion of a grid-connected photovoltaic system in the institution, will contribute to the reduction of costs with electric energy due to the energy contribution of this system, as well as, especially in the days of high solar incidence, there will be a change in the profile of the demand curve, and may even shift or reduce its peak. 


\section{REFERENCES}

1- Urbanetz Jr J. Photovoltaic Systems Connected to Urban Distribution Networks: Their Influence on the Quality of Electric Power and Analysis of Parameters That May Affect Connectivity. [Thesis], 2010; 189. Portuguese

2- National Electrical Energy Agency: Distributed Micro and Mini generators Records made effective at ANEEL - [cited 2017 Jul 10]. Available from: http://www2.aneel.gov.br/scg/gd/GD_Fonte.asp

3- Urbanetz Jr J, Tiepolo GM, Casagrande Jr EF, Tonin FS, Mariano JD. [Photovoltaic Distributed Generation: The Case of UTFPR Photovoltaic Systems in Curitiba]. Congresso Brasileiro de Planejamento Energético. 2016 Sep 26-28;12(5). Portuguese.

4- Pereira EB, Martins FR, Abreu SL, Rüther R. Brazilian Atlas of Solar Energy. São José dos Campos: INPE; 2006. p. 60.

5- National Institute of Meteorology [cited 2016 Aug 5]. Available from: http://www.inmet.gov.br

6- Urbanetz JR J. [Photovoltaic solar energy: fundamentals and design of systems] 2012; p. 12. Portuguese

7- Power Telemetry System [cited 2016 Aug 5]. Available from: http://telemedicao.copel.com/hemera/ hemera.jsp.

8- Rebechi SH. The potential of solar photovoltaic generation connected to the urban distribution system: case study for a feeder with peak daytime load. [Dissertation], 2008; 100. Portuguese. 